\title{
Fabry disease: Guidelines for the evaluation and management of multi-organ system involvement
}

Christine M. Eng, $M D^{1}$, Dominique P. Germain, $M D^{2}$, Maryam Banikazemi, $M D^{3}$, David G. Warnock, $M D^{4}$, Christoph Wanner, $M D^{5}$, Robert J. Hopkin, $M D^{6}$, Jan Bultas, $M D^{7}$, Philip Lee, $M D^{8}$, Katherine Sims, $M D^{9}$, Scott E. Brodie, $M D^{3}$, Gregory M. Pastores, $M D^{10}$, Joerg M. Strotmann, $M D^{5}$, and William R. Wilcox, $M D, P h D^{11}$

\begin{abstract}
Fabry disease is an X-linked metabolic storage disorder due to the deficiency of lysosomal $\alpha$-galactosidase $\mathrm{A}$, and the subsequent accumulation of glycosphingolipids, primarily globotriaosylceramide, throughout the body. Males with classical Fabry disease develop early symptoms including pain and hypohidrosis by the second decade of life reflecting disease progression in the peripheral and autonomic nervous systems. An insidious cascade of disease processes ultimately results in severe renal, cardiac, and central nervous system complications in adulthood. The late complications are the main cause of late morbidity, as well as premature mortality. Disease presentation in female heterozygotes may be as severe as in males although women may also remain asymptomatic. The recent introduction of enzyme replacement therapy to address the underlying pathophysiology of Fabry disease has focused attention on the need for comprehensive, multidisciplinary evaluation and management of the multi-organ system involvement. In anticipation of evidence-based recommendations, an international panel of physicians with expertise in Fabry disease has proposed guidelines for the recognition, evaluation, and surveillance of diseaseassociated morbidities, as well as therapeutic strategies, including enzyme replacement and other adjunctive therapies, to optimize patient outcomes. Genet Med 2006:8(9):539-548.
\end{abstract}

Key Words: agalsidase beta, enzyme replacement therapy, Fabry disease, $\alpha$-Galactosidase A, symptoms, treatment

When one or more of the enzymes required for breakdown of complex macromolecules is deficient, pathologic accumulation occurs within lysosomes, progressively impairing normal cellular function and leading to clinical symptoms. Fabry disease, an Xlinked disorder, is a lysosomal storage disorder caused by deficient activity of $\alpha$-galactosidase A. The primary disease process, i.e., pathologic accumulation of predominantly globotriaosylceramide (GL-3), involves vascular endothelial cells and other cell types such as neural cells, cardiomyocytes, and all types of renal cells, ${ }^{1}$ leading to cellular dysfunction, tissue remodeling, fibrosis, ischemia and, ultimately to severe end-organ damage (Table 1). The classical phenotype is seen in most males and rarely in females. Early disease manifestations such as acropa-

\footnotetext{
From the ${ }^{1}$ Baylor College of Medicine, Houston, Texas; ${ }^{2}$ Hôpital Européen Georges Pompidou, Paris, France; ${ }^{3}$ Mount Sinai School of Medicine, New York, New York; ${ }^{4}$ University of Alabama at Birmingham, Birmingham, Alabama; ${ }^{5}$ University Hospital, Department of Medicine, Wuerzburg, Germany; ${ }^{6}$ Cincinnati Children's Hospital, Cincinnati, Ohio; ${ }^{7}$ Charles University, Prague, Czech Republic; ${ }^{8}$ National Hospital For Neurology \& Neurosurgery, London, United Kingdom; ${ }^{9}$ Massachusetts General Hospital, Boston, Massachusetts; ${ }^{10}$ New York University, New York, New York; ${ }^{11}$ Cedars-Sinai Medical Center, Los Angeles, California.

Christine M. Eng, MD, Department of Molecular and Human Genetics, Baylor College of Medicine, One Baylor Plaza, NAB 2015, Houston, TX 77030.

Submitted for publication September 12, 2005.

Accepted for publication June 8, 2006.
}

DOI: 10.1097/01.gim.0000237866.70357.c6 resthesias, angiokeratoma, and hypohidrosis become apparent in the pediatric years, whereas later in life, kidney, cardiac and central nervous system (CNS) complications develop. Although the pathologic processes are initiated in childhood, the rate of progression from sub-clinical processes to clinical symptoms can differ for each organ. In addition, there are some phenotypes in which not all classically affected organs are involved. The cardiac variant with residual enzymatic activity is seen in males and a variety of attenuated phenotypes are seen in women. ${ }^{1}$

The gene encoding $\alpha$-galactosidase $\mathrm{A}$ has been isolated and sequenced, ${ }^{2,3}$ and currently more than 245 different mutations (missense, nonsense, splice, deletion and insertion errors) have been identified. ${ }^{4}$ Attempts have been made to correlate genotype with clinical outcome, however these efforts have been confounded by the fact that there a very few recurrent mutations and, even within families, the phenotype may vary. The variability in females may be partly accounted for by nonrandom X-chromosome inactivation, but other factors such as genetic modifiers may play a role in both males and females.

Recently, the clinical manifestations, diagnostic strategies, and early efficacy of enzyme replacement therapy (ERT) for Fabry disease have been reviewed. ${ }^{1,5-8}$ Detailed knowledge of the natural history of Fabry disease provides the basis to measure the effects of treatment options. Several registries of clinical data are currently active for Fabry disease, of which the 
Table 1

Pathophysiologic findings in Fabry disease

\begin{tabular}{lc}
\hline Organ system & \multicolumn{1}{c}{ Cell types potentially affected by GL-3 deposits } \\
\hline Kidney & $\begin{array}{c}\text { Podocytes, mesangium, glomerular endothelium, epithelium of Bowman's } \\
\text { capsule, loops of Henle and distal tubule, arterial and arteriolar smooth } \\
\text { muscle and endothelium, interstitial cells }{ }^{11,92}\end{array}$ \\
Cardiac & $\begin{array}{c}\text { Cardiomyocytes, conduction system cells, vascular endothelial and smooth } \\
\text { muscle cells, valvular fibrocytes }\end{array}$
\end{tabular}
muscle cells, valvular fibrocytes ${ }^{93}$

Neurologic

Neurovascular endothelial cells, vasa vasorum, neurons within central and peripheral nervous system, including dorsal root and autonomic ganglia ${ }^{94,95}$

Dermatologic Vascular endothelial cells, smooth muscle cells, fibroblasts, perineurium, eccrine sweat glands, including epithelium ${ }^{64,96,97}$

Ophthalmologic Epithelial cells in the cornea, lens, ${ }^{72}$ vascular endothelial cells ${ }^{75}$

Pulmonary Airway epithelial cells, vascular endothelial cells, smooth muscle cells ${ }^{62,63}$

Gastrointestinal Vascular endothelial and perithelial cells in the small intestine, colon and rectum; smooth muscle cells; autonomic nerve ganglia in the intestinal wall; small unmyelinated neurons and perineurial cells ${ }^{55,99}$

Spectrum of pathophysiologic findings

Glomerular sclerosis, tubular atrophy, interstitial fibrosis ${ }^{13,92}$

LV-hypertrophy; heart failure; stenosis or diffuse narrowing of epicardial vessels; atherosclerotic plaques; coronary vasospasm; thrombotic and thromboembolic complications $s^{9,10}$

Ischemic injury (prothrombotic and occlusive abnormalities) and metabolic failure resulting in: Functional disruption of neuronal cells, loss of small myelinated and unmyelinated fibers; ischemic small vessel multifocal leukoencephalopathy; large vessel ectasia $^{51,78,94}$

Weakening of capillary wall and vascular ectasia within (epi-)dermis; narrowing of small blood vessels around the eccrine sweat glands ${ }^{64,65,98}$

Streaks in corneal epithelium; vasculopathy of the conjunctival and retinal vessels; central retinal artery occlusion; reduced lacrimal secretion ${ }^{75,78}$

Airway narrowing, capillary blockage ${ }^{62}$

Narrowing of mesenteric small blood vessels $\mathrm{s}^{55}$

Narrowing or total occlusion of cochlear vessels ${ }^{48}$; ischemic auditory neuropathy ${ }^{48}$
Fabry Registry (www.fabryregistry.com) is the largest. For the registries to provide aggregate data on natural history and treatment response for all participants, a relatively uniform practice standard would provide a useful framework. Moreover, as the overall care of Fabry patients moves beyond the realm of genetic subspecialists, there is a need for management guidelines for a rare condition in which there may be only a single patient per medical practice.

An international panel of physicians with extensive expertise in the clinical management of patients with Fabry disease collaborated in developing guidelines for the therapeutic management of this condition. The authors, who represent eight subspecialties, performed a comprehensive review of the relevant medical literature on Fabry disease. The outcome of this review was supplemented by the experts' unpublished clinical experiences within their specialties. As prospective, longitudinal registry data are obtained and analyzed, opinion-based guidelines presented here may be modified.

\section{Disease manifestations and management recommendations}

The progressive nature of Fabry disease reflects different cascades of disease processes which may precede clinical symptoms by a significant time period. Lysosomal accumulation can lead to lysosomal and cellular dysfunction, which trigger tissue responses, such as inflammation, that ultimately lead to irreversible damage and renal, cardiac, and CNS complications. Vascular endothelial cell storage may lead to luminal encroachment and occlusion, as well as to altered vascular reac- tivity and a prothrombotic state, ${ }^{9,10}$ leading to ischemic events affecting various sites. Pathophysiologic observations in tissue specimens of Fabry disease patients are summarized in Table 1. As there is no fixed combination and order of organ involvement and disease progression, all relevant organ systems need to be assessed, treated, and monitored individually, as discussed below.

\section{Renal involvement}

Chronic kidney disease (CKD) is a prominent feature of classical Fabry disease and the main cause of premature death in the classical phenotype. Initial manifestations include impaired filtration rate (GFR), proteinuria, and tubular derangements. ${ }^{11}$ Microalbuminuria and blunted concentrating ability have been reported in adolescents. Typically, reduced GFR and proteinuria associated with GL-3 accumulation develop during the third decade in affected males. ${ }^{1,12,13}$ Glomerular sclerosis, tubular atrophy, and interstitial fibrosis result in progressive kidney involvement and failure, at a rate comparable to diabetic nephropathy. Before the availability of dialysis and transplantation, death from kidney failure occurred early in the fifth decade in classically affected males. ${ }^{1,12,13}$ In contrast, a much lower proportion of females suffer progressive renal dysfunction to the point of end-stage renal disease or transplantation. ${ }^{14}$

Kidney outcome may be more directly related to interstitial and glomerular fibrosis and scarring rather than GL-3 deposits in parietal and visceral glomerular epithelial cells; epithelial 
deposits have been demonstrated in heterozygous females with little derangement in kidney function. ${ }^{15-18}$ GL-3 deposits in podocytes have not been directly related to the magnitude of proteinuria or the rates of progression or severity of the kidney involvement in Fabry disease.
The evaluations of kidney function that should be carried out in every Fabry patient are outlined in Table 2 and should include estimates of GFR, total protein, (micro)albumin excretion, and urinary sodium excretion. In early stages of kidney involvement, quantitative estimates of GFR are necessary. While several 24 hour

Table 2

Proposed assessments in Fabry disease patients

\begin{tabular}{|c|c|c|}
\hline Organ system & Assessment & Recommendation \\
\hline \multirow[t]{4}{*}{ General } & $\begin{array}{l}\text { General status, school or work performance, sports, depression, anxiety, } \\
\text { drug use, pedigree update, somatic growth }\end{array}$ & Baseline (at first visit), every 6 months \\
\hline & $\begin{array}{l}\text { Complete physical examination } \\
\text { SF-36 }{ }^{\circledR} \text { Health Survey, or PedsQL }{ }^{\mathrm{TM}} \text { Measurement Mode }\end{array}$ & Baseline, every 6 months \\
\hline & Genetic counseling & Baseline, every 6 months for new issues \\
\hline & Genotype & If not previously determined \\
\hline Kidney $^{a}$ & $\begin{array}{l}\text { Serum electrolytes, creatinine, BUN; } 24 \text { hour urine or spot urine for } \\
\text { total protein/creatinine, albumin/creatinine, sodium, creatinine, } \\
\text { and (optional) GL-3 }\end{array}$ & $\begin{array}{l}\text { Baseline. Every } 3 \text { months if CKD stage } 1 \text { or } 2 \text { and }>1 \\
\text { g/day of proteinuria or CKD stage } 4 \\
\text { Every } 6 \text { months if CKD stage } 3 \\
\text { Every } 12 \text { months if CKD stage } 1 \text { or } 2 \text { and }<1 \mathrm{~g} / \text { day of } \\
\text { proteinuria }\end{array}$ \\
\hline \multirow[t]{6}{*}{ Cardiac } & Palpitations, angina & Baseline, every 6 months \\
\hline & Blood pressure, rhythm & Every evaluation visit \\
\hline & ECG, echocardiography 2-D with Doppler & $\begin{array}{l}\text { Baseline. Every other year for patients } \leq 35 \text { years of } \\
\text { age, every year thereafter }\end{array}$ \\
\hline & Holter monitoring, 30-day event monitoring & $\begin{array}{l}\text { If an arrhythmia is suspected or palpitations are } \\
\text { present }\end{array}$ \\
\hline & MRI, strain rate imaging & Optional \\
\hline & Coronary angiography & If clinical signs of angina \\
\hline \multirow[t]{7}{*}{ Neurologic } & $\begin{array}{l}\text { Acroparesthesias, fatigue, fever, sweating, heat and cold tolerance, joint } \\
\text { pains, stroke-related symptoms, TIA }\end{array}$ & Baseline, every 6 months \\
\hline & Neurologic exam, Brief Pain or McGill Pain Inventory & Baseline, every 6 months \\
\hline & Brain MRI without contrast & $\begin{array}{l}\text { Baseline. At time of a TIA or stroke event or in females } \\
\text { to document CNS involvement }\end{array}$ \\
\hline & Magnetic resonance angiography & If cerebral vasculopathy should be excluded \\
\hline & $\begin{array}{l}\text { Cold and heat intolerance, pain, vibratory thresholds, sweat output, } \\
\text { post-ganglionic sudomotor function, superficial skin blood flow }\end{array}$ & When available \\
\hline & Comorbid stroke risk factors: Cholesterol (Total, LDL, HDL), triglycerides & Anually \\
\hline & $\begin{array}{l}\text { Lipoprotein A, total plasma homocysteine, factor V Leiden (G1691A), } \\
\text { Protein C, Protein S, prothrombin G20210A, antithrombin III, } \\
\text { anticardiolipin antibody, lupus anticoagulant }\end{array}$ & At baseline, single assessment \\
\hline \multirow[t]{2}{*}{ ENT } & Tinnitus, hearing loss, vertigo, dizziness & Baseline, every 6 months \\
\hline & Audiometry, tympanometry, otoacoustic emissions & Baseline, and yearly thereafter \\
\hline \multirow[t]{3}{*}{ Ophthalmologic } & Visual disturbances, light sensitivity & Baseline, every 6 months \\
\hline & $\begin{array}{l}\text { General ophthalmologic exam (slit-lamp, direct ophthalmoscopy, best } \\
\text { corrected visual acuity, visual fields) }\end{array}$ & Baseline, every 12 months \\
\hline & $\begin{array}{l}\text { Retinal dysfunction testing (ERG, color vision testing, visual evoked } \\
\text { potentials, retinal angiography), tear secretion testing }\end{array}$ & If clinically indicated \\
\hline \multirow[t]{2}{*}{ Pulmonology } & Cough, exertional dyspnea, wheezing, exercise intolerance & Baseline, every 6 months \\
\hline & $\begin{array}{l}\text { Spirometry, including response to bronchodilators, treadmill exercise } \\
\text { testing, oximetry, chest X-ray }\end{array}$ & $\begin{array}{l}\text { Baseline, every } 2 \text { years or more frequently for clinical } \\
\text { indications }\end{array}$ \\
\hline \multirow[t]{2}{*}{ Gastrointestinal } & $\begin{array}{l}\text { Postprandial abdominal pain, bloating, diarrhea, nausea, vomiting, early } \\
\text { satiety, difficulty gaining weight }\end{array}$ & Baseline, every 6 months \\
\hline & Endoscopic or radiographic evaluations & If symptoms persist or worsen despite treatment \\
\hline Skeletal & Bone mineral density & Baseline \\
\hline
\end{tabular}

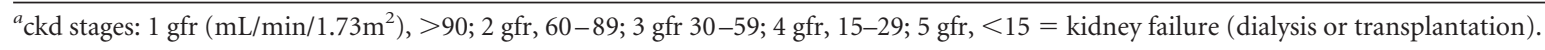


urine collections would be ideal, the utility of "spot" urine protein/creatinine ratios and estimated GFR with the modification of diet with renal disease (MDRD) equation has been established. Assessment of proteinuria and GFR can be used for the staging of $\mathrm{CKD}$, as described in the Kidney Disease Outcomes Quality Initiative (K/DOQI CKD) Guidelines of the United States National Kidney Foundation (Table 2). ${ }^{19}$ Kidney biopsies may be useful as a baseline assessment and in patients with atypical presentations, including a repeat kidney biopsy when disease is progressing despite therapy.

Therapeutic management primarily focuses on the control of blood pressure, lipids, and proteinuria. ${ }^{20,21}$ Angiotensinconverting enzyme (ACE) inhibitors and angiotensin receptor blockers (ARB) are important therapeutic options in all forms of proteinuric renal disease. The most important goals for adjunctive therapy in patients receiving ERT are stabilization of kidney function and reduction of urinary protein and albumin excretion to the absolute minimum, and not necessarily reduction of the systemic blood pressure to a preset goal. Patients may be unable to tolerate significant doses of ACE and ARB blood pressure medications even when they are uptitrated slowly, in part because of the relatively low baseline blood pressures and substandard exercise tolerance. Renal transplantation is undertaken routinely for Fabry disease patients who have reached end-stage renal disease. ${ }^{22,23}$ Of note, GL-3 accumulation does not occur in the transplanted kidney. For patients on dialysis, a pharmacokinetic study showed that agalsidase beta is not lost during standard hemodialysis, and these patients can be infused with agalsidase beta during the course of their routine hemodialysis. ${ }^{24}$

\section{Cardiac involvement}

The heart is frequently involved in the various phenotypic variants of Fabry disease, including women with clinical disease and males with the cardiac variant. In the latter, cardiac manifestations of Fabry disease are prominent and may or may not be accompanied by other manifestations. ${ }^{25}$ In various surveys, $3-12 \%$ of patients with unexplained left ventricular hypertrophy (LVH) have Fabry disease, ${ }^{26-28}$ indicating that Fabry disease should be strongly considered if onset is over 40 years of age, with concentric hypertrophy, and if evidence of major outflow obstruction or long-standing hypertension are absent.

Cardiac events are a key cause of premature death, either due to primary Fabry-related cardiac disease or driven by cardiovascular disease seen in most patients on dialysis, regardless of underlying disease. Among dialysis patients, Fabry patients have increased morbidity and mortality. ${ }^{29}$ The earliest heart abnormalities are shortened PR interval, resting bradycardia, mild valvular insufficiency, and diastolic dysfunction ${ }^{30,31} \mathrm{In}-$ volvement of the conduction system leads to potentially lethal arrhythmias. Permanent cardiac pacing is needed for about $10-20 \%$ of patients. ${ }^{32,33}$

Myocardial GL-3 deposits represent $<1 \%$ of the actual myocardial mass. ${ }^{25}$ Other mechanisms, including inflammation and neuro-hormonal dysregulation have been proposed as stimuli to cardiac hypertrophy. ${ }^{25}$ Hypertrophic cardiomyopathy can occur with or without left ventricular outflow tract obstruction, sometimes leading to significant intraventricular pressure gradients. Left ventricular enlargement and reduced ejection fraction can be seen in advanced stages of the disease, accompanied by clinical signs of congestive heart failure. The use of cardiac transplantation in a Fabry patient has been reported. ${ }^{34}$

Damage to the coronary vascular bed may lead to angina pectoris, variant angina, and myocardial infarction and does not necessarily follow the typical patterns observed in atherosclerosis. Involvement of small, penetrating vessels is predominant. ${ }^{9}$ Both LDL- and HDL-cholesterol are commonly elevated. ${ }^{35}$ Disturbance of the vasodilatative/vasoconstrictive mechanisms favoring the latter may account for the lymphedema in the absence of hypoproteinemia or varices. ${ }^{36}$ Raynaud's phenomenon and vasospastic reactions leading to variant angina are common observations in Fabry patients.

Patients with Fabry disease should be monitored by routine ECG and echocardiography as specified in Table 2. Echocardiography is helpful to document concentric or eccentric LVH with or without left ventricle outflow tract (LVOT) obstruction, presence and grade of diastolic dysfunction, and rarely in advanced stages of the disease, dilated cardiomyopathy and significant valvular regurgitation. Holter (24-hour) monitoring may detect rhythm abnormalities, but 30-day event or loop monitoring can be required. When LVH is present, magnetic resonance imaging (MRI) can help determine the amount of scarring present. Coronary angiography is necessary when clinical signs of angina are present.

Treatment remains mainly symptomatic. Endothelial dysfunction with vasospasm and thrombotic events are treated with ACE-inhibitors, calcium channel blockers and anti-platelet drugs (aspirin, clopidogrel). Dyslipidemia (most commonly, hypercholesterolemia) should be treated with statins. ${ }^{37}$ Permanent cardiac pacing in patients with higher degrees of A-V blocks is used. Left ventricular (LV) outflow tract obstruction leading to significant pressure gradients can be managed conservatively with verapamil. Interventional techniques such as ethanol induced percutaneous transluminal septal myocardial ablation (PTSMA) can be applied where conservative measures fail to bring relief. The use of beta blockers in cases of coronary artery disease should be monitored carefully because of the risk of worsening of bradycardia. ${ }^{38}$ In a typical patient, an ACE or ARB for afterload reduction is the most appropriate, unless there is frank outflow obstruction.

\section{Neurological involvement}

Neurological morbidity is composed of early symptoms related to dysfunction of the peripheral and autonomic nervous systems, as well as late symptoms due to vascular complications in the central nervous system. However, autonomic dysfunction might contribute to vascular events, and primary storage in neurons might also be involved in loss of neurons in the brain. ${ }^{39}$ 
Prothrombotic and occlusive abnormalities, as well as large vessel ectasias, may compromise vascular reactivity and lead to ischemic-hypoxic damage. Given the intraneuronal GL-3 storage, primary cellular metabolic failure may also play a role in the pathophysiology of clinical stroke. In a cohort of 33 Fabry patients, $24 \%$ suffered at least one stroke at first occurrence mean age of 29 years..$^{40}$ Onset of CNS symptoms has been shown to occur earlier in males (age 34) than in females (age 40). ${ }^{41}$ The burden of CNS complications increases with age and one study showed that all patients older than 54 years had cerebrovascular involvement. ${ }^{42}$ Mild dementia can appear late secondary to diffuse leukomalacia, multiple strokes or possibly to lipid storage in hippocampal and frontal lobe neurons. ${ }^{43}$

The earliest symptoms of Fabry disease are often episodic acroparesthesias which have been reported as early as age 2 and relate to small-fiber involvement in the peripheral nervous system. These can occur in both genders as constant burning pain and tingling especially in the feet and hands. Episodic pain crises of extremely severe attacks of sharp neuropathic pain ${ }^{44}$ can last from a few minutes to several weeks and can be accompanied by fatigue, low-grade fever and joint pains. Pain may be triggered by physical activity, exercise, cold or heat exposure, fever, and stress. Additional early manifestations related to autonomic dysfunction include hypo- or anhidrosis, and poor temperature and exercise tolerance, that have been reported as early as age $6^{45}$ and may also be present in females. ${ }^{46}$ Other symptoms include abnormalities of blood pressure regulation, poor cerebrovascular reactivity, impaired pupillary constriction, abnormal gastrointestinal motility with pain, and decreased tear and saliva formation.

Comprehensive neurological evaluation is essential, particularly before the institution of ERT, to assess disease extent and severity. History of pain, including frequency and severity, should be assessed using tools such as the Brief Pain Inventory or the McGill Pain Inventory. Clinical investigations include brain imaging by $\mathrm{CT}$ or, preferably by MRI with $\mathrm{T} 1, \mathrm{~T} 2$ and FLAIR-weighted images. Magnetic resonance angiography (MRA) may be indicated to exclude cerebral vasculopathy. Additional MRI sequences (DWI, ADC) can assist in evaluation at time of transient ischemic attack (TIA) or stroke event. Test methods for monitoring nerve fiber dysfunction ${ }^{47}$ (Table 2) are useful, but not widely available. Laboratory evaluation of comorbid stroke risk factors may identify patients with significantly elevated homocysteine, with a vitamin deficiency state, or with other genetic prothrombotic risk factors (Table 2).

Symptomatic therapy continues to play an important role in the clinical management of Fabry disease. ${ }^{44}$ Phenytoin, carbamazepine oxcarbazepine, gabapentin and/or topiramate are used for treatment of painful crises and acroparesthesias. Patients are advised to self-monitor their activity in order to avoid factors that precipitate pain, limit their exposure to extreme temperatures and maintain hydration. Spraying the skin with water can temporarily help compensate for hypohidrosis.

Aspirin and other platelet-inhibiting agents (such as clopidogrel and ticlopidine) are often recommended as prophylaxis to minimize the risk of stroke. Clopidogrel should be used if aspirin is not tolerated, and both drugs may be indicated in patients who have had a thrombotic stroke or TIA. Proper hydration and avoidance of hypotension and hypertension are important for the maintenance of adequate cerebral perfusion.

\section{ENT involvement}

Until recently, ${ }^{48}$ the otologic manifestations in Fabry disease were underappreciated, although progressive hearing loss predominantly in the high tone range, sudden deafness (often asymmetric), tinnitus, and vertigo with dizziness and nausea were reported decades ago. ${ }^{49,50}$ Hearing loss should be looked for actively since it may not be reported spontaneously. ${ }^{51}$ One study documented self-reported hearing loss in $41 \%$ of 98 male Fabry patients. An abnormal audiogram was obtained in $78 \%$ of these patients. ${ }^{52}$

Study of cochlear function including conventional audiometry, tympanometry, auditory brainstem response (ABR) audiometry, and otoacoustic emissions in 22 male patients disclosed a high prevalence of progressive hearing loss, both of sensorineural origin (23\%) and sudden deafness (32\%), as well as tinnitus aurium $(27 \%))^{48}$

A detailed medical history of tinnitus, hearing loss, and vertigo should be carefully documented. Audiometry should be performed at baseline and if clinical symptoms appear. Sudden hearing loss can be managed with infusion of vasodilators and steroids. Hearing aids or cochlear implants should be considered in case of advanced deafness. Episodes of vertigo can be severe and associated nausea may require trimethobenzamide, prochlorperazine, or other antinausea drugs.

\section{Gastrointestinal manifestations}

Gastrointestinal symptoms may include postprandial abdominal pain and bloating followed by multiple bowel movements and chronic or intermittent diarrhea, nausea, vomiting and early satiety. ${ }^{53}$ Many affected males have difficulty gaining weight $^{54}$ and are in general smaller in height and weight than their unaffected sibs. The symptoms typically begin in adolescence, sometimes before the age of 10 and often as primary symptom. ${ }^{55}$ In a cohort of 25 pediatric patients, $80 \%$ experienced symptoms of nonspecific enteropathy (e.g., abdominal pain, diarrhea). ${ }^{56}$ Generally, symptoms are more frequent and appear earlier among males. ${ }^{57,58}$

The medical history should focus on bowel habits, weight gain and dietary aspects. Radiographic or endoscopic evaluation may be indicated. Delayed gastric emptying and dyspepsia have been successfully treated symptomatically, to some extent, with metoclopramide ${ }^{59}$ and $\mathrm{H}-2$ blockers, respectively.

\section{Pulmonary manifestations and exercise intolerance}

Pulmonary involvement may manifest as chronic cough, dyspnea with exercise, and wheezing. Chronic cough is a common complaint in men as well as women. ${ }^{60}$ While the cough may be worsened by reactive airway disease or tobacco use, it can occur in individuals without these risk factors. ${ }^{61,62}$ Spirometry may show signs of obstructive ventilatory impairment, ${ }^{61,62}$ particularly with decreased $\mathrm{FEV}_{1}, \mathrm{FEV}_{1} / \mathrm{FVC}$, or $\mathrm{FEF}_{25-75}{ }^{60}$ 
Exercise intolerance in Fabry disease is typically attributed to hypohidrosis, pulmonary disease, or cardiomyopathy, but can begin early in childhood and is not uncommon in female patients. A recent study revealed a decrease in diastolic blood pressure equal to or $>10 \mathrm{mmHg}$ during exercise testing in approximately half of the patients studied, with the largest declines occurring in females. ${ }^{60}$

Spirometry and exercise testing with monitoring of blood pressure should be performed at baseline and every two years thereafter. This testing, along with the ECG and echocardiogram, is especially helpful for distinguishing causes of exercise intolerance and fatigue. If pulmonary involvement is significant, induced sputum may show typical Fabry lamellar inclusions, ${ }^{63}$ but bronchoscopy and/or a lung biopsy may be required to rule out other etiologies for the pulmonary disease.

\section{Dermal manifestations}

Dermatological disturbances include the cutaneous vascular lesions (angiokeratomas), and, as previously discussed, anhidrosis, or more commonly hypohidrosis. Angiokeratomas, caused by weakening of the capillary wall and vascular ectasia within the epidermis and dermis, ${ }^{64,65}$ are one of the earliest clinical signs and may be seen in both genders. They usually manifest between 5 and 13 years of age. ${ }^{66}$ They initially appear as small, slightly raised, purplish-red, non-blanching angiectases. With age, there is progressive increase in the number and size of these lesions. The hips, back, thighs, buttocks, penis, and scrotum are commonly affected, as well as the oral mucosa and conjunctiva. ${ }^{67}$ The large genital lesions are particularly susceptible to thrombosis ${ }^{68}$ and bleeding. Among female carriers, frequencies of occurrence of angiokeratomas up to $35 \%$ have been reported. ${ }^{69}$

The results of various laser methods (e.g., variable pulse width 532-nm Neodymium, and flash lamp-pumped dye laser) in treating angiokeratomas of Fabry disease have been mixed or discouraging. ${ }^{70}$ In addition, this treatment did not prevent formation of new lesions. More pedunculated lesions may be treated with a series of liquid nitrogen treatments prior to laser therapy. Topical moisturizers can be helpful in preventing skin fissures due to hypohidrosis and secondary infections.

\section{Ophthalmologic manifestations}

The ocular findings play an important role in the early recognition of Fabry disease. Corneal manifestations are reported to be present in over $90 \%$ of the patients..$^{71}$ The best-known ocular sign of Fabry disease is the pattern of pale, spiral streaks in the corneal epithelium known as "cornea verticillata."72; Mild forms have been observed in $88 \%$ of a cohort of pediatric patients. ${ }^{56}$ The streaks may vary in color from pale gray to brownish or yellowish. In some patients, the corneal involvement is quite homogeneous, appearing as a diffuse, even corneal haze, with little or no evident streaking. The pattern of streaks is often most prominent in heterozygous females..$^{73,74}$ The corneal haze or streaks associated with Fabry disease rarely, if ever, cause visual symptoms. In some cases, there may be a history of difficulties seeing under conditions of severe veiling glare, as when driving toward oncoming headlights.

Fabry disease patients are also susceptible to the development of opacities of the crystalline lens, or cataracts. The most characteristic lesion is a unique pattern of branching opacities lying just inside the posterior lens capsule. ${ }^{72}$ These dendritic opacities do not impair visual acuity, and do not represent an indication for cataract extraction. They are best visualized after dilation of the pupils, viewing the posterior lens capsule in the reflected red light of the fundus with a slit-lamp biomicroscope.

Vasculopathy often manifests in the conjunctival blood vessels, most commonly those in the inferior sectors of the bulbar conjunctiva. ${ }^{72}$ The most typical conjunctival lesion is the presence of small numbers of saccular aneurysms, best visualized with the slit-lamp biomicroscope. The prominent conjunctival vessels do not cause discomfort, and are not unusually prone to hemorrhage. Vascular involvement of the retina is common, leading to narrowing of the retinal arterioles, dilation and irregularity of the retinal veins, and exaggerated tortuosity of the retinal vessels. ${ }^{75}$ Vision in Fabry disease patients is rarely impaired due to the retinal vasculopathy but sudden visual loss due to central retinal artery occlusion ${ }^{72,76}$ and ischemic optic neuropathy have been encountered. ${ }^{77}$ Finally, lacrimal secretion may be reduced as a consequence of vascular involvement or GL-3 deposition in the lacrimal gland. ${ }^{78}$

The ocular stigmata of Fabry disease rarely if ever cause significant impairment of vision and, as a rule, do not require treatment. ${ }^{79}$ Best corrected visual acuity and visual fields should be tested periodically. If clinically indicated, retinal dysfunction testing (electroretinogram (ERG), color vision testing, visual evoked potentials, retinal angiography) and tear secretion testing may confirm ophthalmologic pathology.

\section{Skeletal manifestations}

A recent prospective study investigated bone involvement in 23 male patients with a mean age of 31 years. Bone mineral density (BMD) measurement of the lumbar spine and femoral neck revealed either osteopenia or osteoporosis in $88 \%$ of the patients. ${ }^{80}$ It is recommended to perform initial assessment and long-term follow-up of BMD, as well as to prevent osteoporotic fractures.

\section{Enzyme replacement therapy}

Clinical research programs of enzyme replacement therapy (ERT) for Fabry disease led to commercial availability of agalsidase alpha (Replagal ${ }^{\circledR}$, Shire Human Genetic Therapies, Inc. $)^{81,82}$ and agalsidase beta (Fabrazyme ${ }^{\circledR}$, Genzyme Corp. ${ }^{83,84}$ in most European countries in 2001, and for agalsidase beta in the US in 2003. Infused $\alpha$-galactosidase $\mathrm{A}$ is taken up by vascular endothelial and parenchymal cells into lysosomes, presumably through the mannose- 6 phosphate, mannose and asialoglycoprotein receptors on the surface of the target cells. Both products are very similar, with comparable specific activities per $\mathrm{mg}$ and glycosylation patterns, ${ }^{85}$ as well as complete cross-reactivity of IgG anti- 
bodies to these products. ${ }^{86}$ Reduction of symptoms and prevention of late complications are key therapeutic goals for ERT. Organ systems must be assessed separately and at regular intervals in order to monitor the effectiveness of treatment (Table 2).

Treatment with both agalsidase alpha ${ }^{82}$ and agalsidase beta ${ }^{84}$ have been shown to reduce GL-3 inclusions. Patients receiving agalsidase beta for at least 5 years showed no decline in renal function unless there was prominent renal sclerosis at baseline. However, TIAs and strokes continued to occur, emphasizing the need for adjunctive therapies. The peripheral neuropathy and hypohidrosis improve slowly. Late complications in older patients may be forestalled. In a randomized, placebo-controlled trial, 51 Fabry patients representing both genders received biweekly agalsidase beta infusions of $1 \mathrm{mg} / \mathrm{kg}$, while 31 patients received placebo. All patients had mild-to moderate renal disease at baseline and median treatment duration was 18.5 months. Agalsidase beta significantly reduced the risk of reaching the composite endpoint of major renal, cardiac, cerebrovascular events, or death by $61 \%(P=0.034)$ in the per protocol population, after adjusting for the baseline imbalance in proteinuria between the treatment groups. Beneficial effects on estimated GFR and serum creatinine levels were more pronounced in patients who began agalsidase beta at less advanced stages of renal dysfunction. 87,88

In the authors' experience, proteinuria may be reversible if treatment is started early, but it is also clear that lost renal function is not recovered. Predictive factors for therapeutic outcome may include advanced renal pathology (e.g., interstitial fibrosis, tubular atrophy, glomerulosclerosis), impaired GFR, and severity of baseline proteinuria. A reduction of severe cardiac events appears consistent with earlier findings. ERT has been shown to reduce myocardial storage of GL-3, ${ }^{84}$ and a significant reduction in LV mass and improvement in intracardiac conduction (QRS complex) were observed with agalsidase beta therapy. ${ }^{89}$ Another study demonstrated significant improvement of myocardial regional function and reduction of LV mass with agalsidase beta. ${ }^{90}$ The latter observation was also made in a separate study of agalsidase alpha in females. ${ }^{91}$

Consensus guidelines for both adjunctive therapies and preventive measures are presented in Tables 3 and 4 . The patient's treatment and follow-up evaluations should be supervised by a physician experienced in the management of patients with Fabry disease or other inherited metabolic diseases. Based on current knowledge, every male Fabry patient should be offered ERT, irrespective of the stage of CKD (Table 3).

\section{Fabry disease in females}

The mean age of onset of disease complications in females and the age of death appear to be later than in males. ${ }^{14}$ Affected females may display all of the classical symptoms but previously unsuspected Fabry disease has also been found in women with isolated organ involvement..$^{28}$ The frequency of hypertrophic cardiomyopathy and of cerebrovascular accidents (stroke, transient ischemic attacks) may be increased in females over the age of $40 .{ }^{57}$ DNA-based diagnosis rather than enzyme ac-
Table 3

Current guidelines for instituting enzyme replacement therapy in Fabry disease patients

\begin{tabular}{ll}
\hline Fabry Population & \multicolumn{1}{c}{ Guideline for Instituting ERT } \\
\hline Adult males $(>16 \mathrm{y})$ & At time of diagnosis of Fabry disease \\
Pediatric males & $\begin{array}{c}\text { At time of development of significant } \\
\text { symptoms }{ }^{a} \text { or } \\
\text { If asymptomatic, consider at } 10-13 \mathrm{yr}\end{array}$ \\
Females (all ages) & $\begin{array}{c}\text { Monitor; institute if significant } \\
\text { symptoms } \mathrm{s}^{a} \text { or evidence of } \\
\text { progression of organ involvement }\end{array}$ \\
\hline
\end{tabular}

${ }^{a}$ See text for explanation.

tivity testing is required in females with either a positive family history or symptoms suggesting Fabry disease. Once the diagnosis is confirmed by molecular methods, the disease burden needs to be assessed clinically. A biopsy of the affected organ (the kidney, or more rarely, the heart) may be required before starting ERT to document the extent of GL-3 storage and to exclude other etiologies. Asymptomatic women can be evaluated every year, but symptomatic women should be monitored every six months, as is recommended for males.

Females with Fabry disease should be offered ERT if they manifest significant symptoms or show evidence of progressive end organ Fabry involvement including: chronic acroparesthesias resistant to conventional therapy, persistent proteinuria (>300 mg/24 hours), GFR below $80 \mathrm{~mL} /$ minute $/ 1.73 \mathrm{~m}^{2}$, clinically significant cardiac involvement, a previous cerebrovascular accident or history of transient ischemic attacks, or ischemic changes on brain MRI (Table 3). Other possible considerations include symptoms unresponsive to other forms of medical management, including chronic, disabling gastrointestinal dysfunction, pulmonary involvement, or abnormal blood pressure regulation during exercise testing.

\section{Pediatric Fabry disease}

Until recently, descriptions of the early, often subtle, presentations of Fabry disease were scarce, partly because the diagnosis was usually made well into adulthood. Recent reports have helped to clarify the natural history. In one study, onset of symptoms occurred earlier in males (mean age 10.9 years) than in females (22.6 years). The mean delay between first symptoms and diagnosis was 13.7 years for males and 16.3 years for affected women. ${ }^{57}$ Most often, a positive family history leads to diagnosis in childhood. For affected children, particular attention should be paid to pain, hypohidrosis, gastrointestinal symptoms, school performance, level of activity, and development of proteinuria. Physical findings are likely to be limited to a few angiokeratoma and the characteristic eye findings.

When to initiate ERT in children is an additional area in which clear, evidence-based recommendations cannot be given at present. The authors agree that, once the diagnosis is confirmed, it is important to institute treatment at the onset of clinically significant symptoms. Boys who have few symptoms 
Table 4

Adjunctive therapies and preventive measures in Fabry disease patients for common Fabry related morbidities

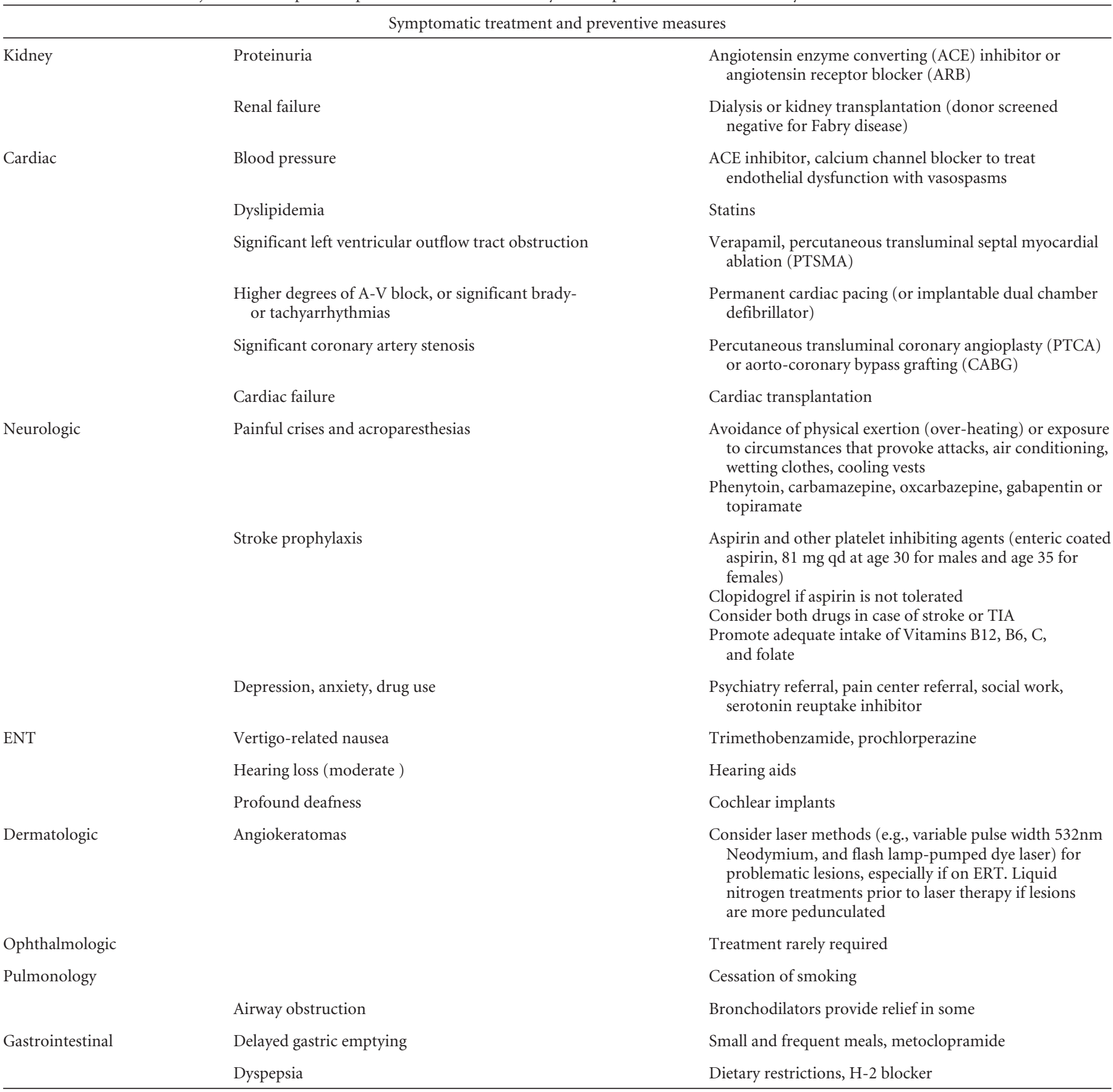

should be considered for ERT around the age of 10-13 years, but some patients begin treatment earlier. There is increasing evidence that suggests that ERT is most beneficial in terms of clinical outcome when initiated early in the disease process, i.e., before irreversible changes occur in key tissues and organs, and it may be anticipated that the incidence of serious complications may be reduced. ${ }^{88}$ The timing of ERT initiation in boys is a collective decision between medical professionals, family, and the patient (Table 3 ).

\section{Perspectives}

Therapeutic management of Fabry disease requires a multidisciplinary approach by medical specialists experienced in treating this rare condition. Such a team approach necessitates active participation and communication between the geneticist, nephrologist, cardiologist, neurologist, and others.

Comprehensive monitoring of Fabry patients, regardless of age, sex, or treatment with ERT, should be conducted at regular intervals. Our proposed guidelines for these assessments are 
summarized in Table 2. Data collected in patients representing the entire disease spectrum, and contributed to Fabry disease patient registries, will allow for further clarification of the response to treatment and better define the optimal care for these complex patients.

\section{References}

1. Desnick R, Ioannou Y, Eng C. alpha-Galactosidase A deficiency: Fabry disease. In: Scriver CR BA, Sly WS, Valle D. ed. The Metabolic and Molecular Bases of Inherited Disease. 8th ed. New York: McGraw-Hill;2001:3733-3774.

2. Kornreich R, Desnick RJ, Bishop DF. Nucleotide sequence of the human alphagalactosidase A gene. Nucleic Acids Res 1989;17:3301-3302.

3. Bishop DF, Calhoun DH, Bernstein HS, Hantzopoulos P, et al. Human alpha-galactosidase A: nucleotide sequence of a cDNA clone encoding the mature enzyme. Proc Natl Acad Sci U S A 1986;83:4859-4863.

4. Garman SC, Garboczi DN. The molecular defect leading to Fabry disease: structure of human alpha-galactosidase. J Mol Biol 2004;337:319-335.

5. Pastores GM, Thadhani R. Advances in the management of Anderson-Fabry disease: enzyme replacement therapy. Expert Opin Biol Ther 2002;2:325-333.

6. Germain DP. Fabry disease: recent advances in enzyme replacement therapy. Expert Opin Investig Drugs 2002;11:1467-1476.

7. Desnick RJ. Enzyme replacement therapy for Fabry disease: Lessons from two alphagalactosidase A orphan products and one FDA approval. Expert Opin Biol Ther 2004;4:1167-1176.

8. Warnock DG. Fabry disease: diagnosis and management, with emphasis on the renal manifestations. Curr Opin Nephrol Hypertens 2005;14:87-95.

9. Kampmann C, Wiethoff CM, Perrot A, Beck M, et al. The heart in Anderson Fabry disease. Zeitschrift fur Kardiologie Oct 2002;91:786-795.

10. DeGraba T, Azhar S, Dignat-George F, Brown E, et al. Profile of endothelial and leukocyte activation in Fabry patients. Ann Neurol 2000;47:229-233.

11. Sessa A, Meroni M, Battini G, Maglio A, et al. Renal pathological changes in Fabry disease. J Inherit Metab Dis 2001;24:66-70.

12. Desnick RJ, Brady R, Barranger J, Collins AJ, et al. Fabry disease, an under-recognized multisystemic disorder: expert recommendations for diagnosis, management, and enzyme replacement therapy. Ann Intern Med 2003;138:338-346.

13. Branton MH, Schiffmann R, Sabnis SG, Murray GJ, et al. Natural history of Fabry renal disease: influence of alpha-galactosidase A activity and genetic mutations on clinical course. Medicine (Baltimore) 2002;81:122-138

14. Waldek S. Burden of Fabry disease in females and the importance of early therapy: An analysis of Fabry Registry Data. J Inherit Metab Dis 2005;28(Suppl 1):165.

15. Gubler MC, Lenoir G, Grunfeld JP, Ulmann A, et al. Early renal changes in hemizygous and heterozygous patients with Fabry's disease. Kidney Int 1978;13:223-235.

16. Farge D, Nadler S, Wolfe LS, Barre P, et al. Diagnostic value of kidney biopsy in heterozygous Fabry's disease. Arch Pathol Lab Med 1985;109:85-88.

17. Marguery MC, Giordano F, Parant M, Samalens G, et al. Fabry's disease: heterozygous form of different expression in two monozygous twin sisters. Dermatology 1993;187:9-15.

18. Rodriguez FH, Hoffmann, EO, Ordinario AT, Baliga M. Fabry's disease in a heterozygous woman. Arch Pathol Lab Med 1985;109:89-91.

19. K/DOQI clinical practice guidelines for chronic kidney disease: evaluation, classification, and stratification. Am J Kidney Dis 2002;39:S1-S266.

20. Gaede P, Vedel P, Larsen N, Jensen GV, et al. Multifactorial intervention and cardiovascular disease in patients with type 2 diabetes. N Engl J Med 2003;348:383-393.

21. Remuzzi G, Schieppati A, Ruggenenti P. Clinical practice. Nephropathy in patients with type 2 diabetes. N Engl J Med 2002;346:1145-1151.

22. Donati D, Sabbadini MG, Capsoni F, Baratelli L, et al. Immune function and renal transplantation in Fabry's disease. Proc Eur Dial Transplant Assoc Eur Ren Assoc 1985;21:686-692.

23. Donati D, Novario R, Gastaldi L. Natural history and treatment of uremia secondary to Fabry's disease: an European experience. Nephron 1987;46:353-359.

24. Kosch M, Koch HG, Oliveira JP, Soares C, et al. Enzyme replacement therapy administered during hemodialysis in patients with Fabry disease. Kidney Int 2004;66: 1279-1282.

25. Elleder M, Bradova V, Smid F, Budesinsky M, et al. Cardiocyte storage and hypertrophy as a sole manifestation of Fabry's disease. Report on a case simulating hypertrophic non-obstructive cardiomyopathy. Virchows Arch A Pathol Anat Histopathol 1990;417:449-455.

26. Nakao S, Takenaka T, Maeda M, Kodama C, et al. An atypical variant of Fabry's disease in men with left ventricular hypertrophy. N Engl J Med 1995;333:288-293.

27. Sachdev B, Takenaka T, Teraguchi H, Tei C, et al. Prevalence of Anderson-Fabry disease in male patients with Late Onset Hypertrophic Cardiomyopathy. Circulation 2002;105:1407-1411.
28. Chimenti C, Pieroni M, Morgante E, Antuzzi D, et al. Prevalence of Fabry disease in female patients with late-onset hypertrophic cardiomyopathy. Circulation 2004;110: 1047-1053.

29. Thadhani R, Wolf M, West ML, Tonelli M, et al. Patients with Fabry disease on dialysis in the United States. Kidney Int 2002;61:249-255.

30. Linhart A, Palecek T, Bultas J, Ferguson JJ, et al. New insights in cardiac structural changes in patients with Fabry's disease. Am Heart J 2000;139:1101-1108.

31. Ries M, Ramaswami U, Parini R, Lindblad B, et al. The early clinical phenotype of Fabry disease: a study on 35 European children and adolescents. Eur J Pediatr 2003; 162:767-772.

32. Maier S, Breunig F, Knoll A, et al. ECG-changes in Fabry disease patients under 12 months of enzyme replacement therapy. German J Cardiology 2004;93 3:166.

33. Shah J, Mehta A, Hughes D, et al. Arrhythmia in Anderson-Fabry disease. Eur Heart Journal 2004;25:539.

34. Cantor WJ, Daly P, Iwanochko M, Clarke JT, et al. Cardiac transplantation for Fabry's disease. Can J Cardiol 1998;14:81-84.

35. Cartwright DJ, Cole AL, Cousins AJ, Lee PJ. Raised HDL cholesterol in Fabry disease: response to enzyme replacement therapy. J Inherit Metab Dis 2004;27:791-793.

36. Amann-Vesti BR, Gitzelmann G, Widmer U, Bosshard NU, et al. Severe lymphatic microangiopathy in Fabry disease. Lymphat Res Biol 2003;1:185-189.

37. O'Connor PJ, Gray RJ, Maciosek MV, Fillbrandt KM, et al. Cholesterol levels and statin use in patients with coronary heart disease treated in primary care settings. Prev Chronic Dis 2005;2 :A05.

38. Ko DT, Hebert PR, Coffey CS, Curtis JP, et al. Adverse effects of beta-blocker therapy for patients with heart failure: a quantitative overview of randomized trials. Arch Intern Med 2004;164:1389-1394.

39. Kahn P. Anderson-Fabry disease: a histopathological study of three cases with observations on the mechanism of production of pain. J Neurol Neurosurg Psychiatry 1973;36:1053-1062.

40. Grewal RP. Stroke in Fabry's disease. J Neurol 1994;241:153-156.

41. Mitsias P, Levine SR. Cerebrovascular complications of Fabry's disease. Ann Neurol 1996;40:8-17.

42. Jardim L, Vedolin L, Schwartz IV, Burin MG, et al. CNS involvement in Fabry disease: clinical and imaging studies before and after 12 months of enzyme replacement therapy. J Inherit Metab Dis 2004;27:229-240.

43. Mendez MF, Stanley TM, Medel NM, Li Z, et al. The vascular dementia of Fabry's disease. Dement Geriatr Cogn Disord 1997;8:252-257.

44. MacDermot J, MacDermot KD. Neuropathic pain in Anderson-Fabry disease: pathology and therapeutic options. Eur J Pharmacol 2001;429:121-125.

45. Shelley ED, Shelley WB, Kurczynski TW. Painful fingers, heat intolerance, and telangiectases of the ear: easily ignored childhood signs of Fabry disease. Pediatr Dermatol 1995;12:215-219.

46. Yamamoto K, Sobue G, Iwase S, Kumazawa K, et al. Possible mechanism of anhidrosis in a symptomatic female carrier of Fabry's disease: an assessment by skin sympathetic nerve activity and sympathetic skin response. Clin Auton Res 1996;6:107-110.

47. Hilz MJ. Evaluation of peripheral and autonomic nerve function in Fabry disease. Acta Paediatr Suppl 2002;91:38-42.

48. Germain D, Avan P, Chassaing A, Bonfils P. Patients affected with Fabry disease have an increased incidence of progressive hearing loss and sudden deafness: A study of twenty-two hemizygous male patients. BMC Medical Genetics 2002;3:10.

49. Bird TD, Lagunoff D. Neurological manifestations of Fabry disease in female carriers. Ann Neurol 1978;4:537-540.

50. De Groot W. Angiokeratoma corporis diffusum Fabry. Dermatologica 1964;128: 321-349.

51. Morgan SH, Rudge P, Smith SJ, Bronstein AM, et al. The neurological complications of Anderson-Fabry disease (alpha- galactosidase A deficiency)-investigation of symptomatic and presymptomatic patients. Q J Med 1990;75 (277):491-507.

52. MacDermot KD, Holmes A, Miners AH. Anderson-Fabry disease: clinical manifestations and impact of disease in a cohort of 98 hemizygous males. J Med Genet 2001;38:750-760.

53. Banikazemi M, Ullman T, Desnick RJ. Gastrointestinal manifestations of Fabry disease: Clinical response to enzyme replacement therapy. Mol Genet Metab 2005; 85:255-259.

54. Nelis GF, Jacobs GJ. Anorexia, weight loss, and diarrhea as presenting symptoms of angiokeratoma corporis diffusum (Fabry-Anderson's disease). Dig Dis Sci 1989;34: 1798-1800.

55. Sheth KJ, Werlin SL, Freeman ME, Hodach AE. Gastrointestinal structure and function in Fabry's disease. Am J Gastroenterol 1981;76:246-251.

56. Ries M, Gupta S, Moore DF, Sachdev V, et al. Pediatric Fabry disease. Pediatrics 2005;115:E344-E355.

57. Mehta A, Ricci R, Widmer U, Dehout F, et al. Fabry disease defined: baseline clinical manifestations of 366 patients in the Fabry Outcome Survey. Eur J Clin Invest 2004, $34: 236-242$. 


\section{Eng et al.}

58. Galanos J, Nicholls K, Grigg L, Kiers L, et al. Clinical features of Fabry's disease in Australian patients. Internal Medicine Journal 2002;32:575-584.

59. Argoff CE, Barton NW, Brady RO, Ziessman HA. Gastrointestinal symptoms and delayed gastric emptying in Fabry's disease: response to metoclopramide. Nucl Med Commun 1998;19:887-891.

60. Bierer G, Kamangar N, Galfe D, Wilcox W, et al. Cardiopulmonary exercise testing in Fabry disease. Respiration 2005;72:504-511.

61. Rosenberg DM, Ferrans VJ, Fulmer JD, Line BR, et al. Chronic airflow obstruction in Fabry's disease. Am J Med 1980;68:898-905.

62. Brown LK, Miller A, Bhuptani A, Sloane MF, et al. Pulmonary involvement in Fabry disease. Am J Respir Crit Care Med 1997;155:1004-1010.

63. Kelly MM, Leigh R, McKenzie R, Kamada D, et al. Induced sputum examination: diagnosis of pulmonary involvement in Fabry's disease. Thorax 2000;55:720-721.

64. Lao LM, Kumakiri M, Mima H, Kuwahara H, et al. The ultrastructural characteristics of eccrine sweat glands in a Fabry disease patient with hypohidrosis. J Dermato Sci 1998;18:109-117.

65. Schiller PI, Itin PH. Angiokeratomas: an update. Dermatology 1996;193:275-282.

66. Hurwitz S. Inborn errors of metabolism. Clinical Pediatric Dermatology, 3rd Edition. Philadelphia:W.B. Saunders, 2003.

67. Desnick RJ, Banikazemi M. Fabry Disease: alpha-Galactosidase A Deficiency (Angiokeratoma Corporis Diffusum Universale). Fitzpatrick's Dermatology In: General Medicine, 6th Edition. McGraw-Hill. 2003.

68. Thurberg BL, Randolph Byers H, Granter SR, Phelps RG, et al. Monitoring the 3 -year efficacy of enzyme replacement therapy in fabry disease by repeated skin biopsies. J Invest Dermatol 2004;122:900-908.

69. MacDermot KD, Holmes A, Miners AH. Anderson-Fabry disease: clinical manifestations and impact of disease in a cohort of 60 obligate carrier females. J Med Genet 2001;38:769-775

70. Mohrenschlager M, Braun-Falco M, Ring J, Abeck D. Fabry disease: Recognition and management of cutaneous manifestations. Am J Clin Dermatol 2003;4:189-196.

71. Sher NA, Reiff W, Letson RD, Desnick RJ. Central retinal artery occlusion complicating Fabry's disease. Arch Ophthalmol 1978;96:815-817.

72. Franceschetti AT. Fabry disease: ocular manifestations. Birth Defects Orig Artic Ser 1976;12:195-208.

73. Lou HO, Heidensleben E, Larsen HW. The value of ocular findings in the diagnosis of angiokeratoma corporis diffusum (Fabry's disease). Acta Ophthalmol 1970;48: 1185-1194.

74. Colombi A, Kostyal A, Bracher R, Gloor F, et al. Angiokeratoma corporis diffusumFabry's disease. Helv Med Acta 1967;34:67-83.

75. Sher NA, Letson RD, Desnick RJ. The ocular manifestations in Fabry's disease. Arch Ophthalmol 1979;97:671-676.

76. Andersen MV, Dahl H, Fledelius H, Nielsen NV. Central retinal artery occlusion in a patient with Fabry's disease documented by scanning laser ophthalmoscopy. Acta Ophthalmol (Copenh) 1994;72:635-638.

77. Abe H, Sakai T, Sawaguchi S, Hasegawa S, et al. Ischemic optic neuropathy in a female carrier with Fabry's disease. Ophthalmologica 1992;205:83-88.

78. Orssaud C, Dufier J, Germain D. Ocular manifestations in Fabry disease: a survey of 32 hemizygous male patients. Ophthalmic Genet 2003;24:129-139.

79. Okubo H. Several functional and fluorescein fundus angiographic findings in Fabry's disease. Ophthalmologica 1988;196:132-136.
80. Germain DP, Benistan K, Boutouyrie P, Mutschler C. Osteopenia and osteoporosis: previously unrecognized manifestations of Fabry disease. Clin Genet 2005;68:93-95.

81. Schiffmann R, Murray GJ, Treco D, Daniel P, et al. Infusion of alpha-galactosidase A reduces tissue globotriaosylceramide storage in patients with Fabry disease. Proc Natl Acad Sci U S A 2000;97:365-370.

82. Schiffmann R, Kopp JB, Austin HA, Sabnis S, et al. Enzyme replacement therapy in fabry disease: a randomized controlled trial. JAMA 2001;285:2743-2749.

83. Eng CM, Banikazemi M, Gordon RE, Goldman M, et al. A phase $1 / 2$ clinical trial of enzyme replacement in Fabry disease: pharmacokinetic, substrate clearance, and safety studies. Am J Hum Genet 2001;68:711-722.

84. Eng CM, Guffon N, Wilcox WR, Germain DP, et al. Safety and efficacy of recombinant human alpha-galactosidase A- replacement therapy in Fabry's disease. N Engl J Med 2001;345:9-16.

85. Lee K, Jin X, Zhang K, Copertino L, et al. A biochemical and pharmacologica comparison of enzyme replacement therapies for the glycolipid storage disorder Fabry disease. Glycobiology 2003;13:305-313.

86. Linthorst GE, Hollak CE, Donker-Koopman WE, Strijland A, et al. Enzyme therapy for Fabry disease: neutralizing antibodies toward agalsidase alpha and beta. Kidney Int 2004;66:1589-1595.

87. Desnick RJe. Clinical benefit of Fabrazyme ${ }^{\circledR}$ (agalsidase beta) in Fabry disease: Results of the Phase 4 Study. ESHG, Vienna, Austria. 2005.

88. Waldek Se. Clinical benefit of Fabrazyme agalsidase beta therapy in Fabry disease: Results of the phase 4 study. LSD Sympsosium Athens, Greece 2005.

89. Pastores GM, Thadhani R. Enzyme-replacement therapy for Anderson-Fabry disease. Lancet 2001;358:601-603.

90. Weidemann F, Breunig F, Beer M, Sandstede J, et al. Improvement of cardiac func tion during enzyme replacement therapy in patients with Fabry disease: a prospective strain rate imaging study. Circulation 2003;108:1299-1301.

91. Beck M, Ricci R, Widmer U, Dehout F, et al. Fabry disease: overall effects of agalsidase alfa treatment. Eur J Clin Invest 2004;34:838-844.

92. Desnick RJ, Wasserstein MP, Banikazemi M. Fabry disease (alpha-galactosidase A deficiency): renal involvement and enzyme replacement therapy. Contrib Nephrol 2001;136:174-192.

93. Linhart A, Magage S, Palecek T, Bultas J. Cardiac involvement in Fabry disease. Acto Paediatr Suppl 2002;91:15-20.

94. Kolodny E, Pastores G. Anderson-Fabry disease: extrarenal, neurologic manifestations. J Am Soc Nephrol 2002;13:S150-S153.

95. Dutsch M, Marthol H, Stemper B, Brys M, et al. Small fiber dysfunction predominates in Fabry neuropathy. J Clin Neurophysiol 2002;19:575-586.

96. Mullem PJV, Ruiter M. Fine structure of the skin in angiokeratoma corporis diffusum (Fabry's disease). J Pathol 1970;101:221-226.

97. van Mullem PJ. Ultrastructure of lipid bodies and lysosomes in the skin in Fabry's disease (angiokeratoma corporis diffusum). Arch Belg Dermatol Syphiligr 1972;28: 41-49.

98. Palungwachira P, Yaguchi H. The ultrastructural study in a case of Fabry disease J Med Assoc Thai 2002;85:842-849.

99. O’Brien, BD, Shnitka TK, McDougall R, Walker K, et al. Pathophysiologic and Ultrastructural Basis for Intestinal Symptoms in Fabry's Disease. Gastroenterology 1982 82:957-962. 